\title{
Performance of Radar Absorbing Nanocomposites by Waveguide Measurements
}

\author{
Jefferson Leixas Capitaneo ${ }^{\mathrm{a}}$, Valeska da Rocha Caffarena ${ }^{\mathrm{b} *}$, \\ Tsuneharu Ogasawarac, Magali Silveira Pinho ${ }^{d}$ \\ anstituto de Macromoléculas - IMA, Universidade Federal do Rio de Janeiro - UFRJ \\ ${ }^{\mathrm{b}}$ PETROBRAS - Gás \& Energia - Corporativo, \\ Tecnologia para Processos de Gás e Energia, Tecnologia para Processos de Gás Natural \\ 'Programa de Eng. Metalúrgica e de Materiais, COPPE, \\ Universidade Federal do Rio de Janeiro - UFRJ \\ ${ }^{\mathrm{d} I n s t i t u t o ~ d e ~ P e s q u i s a s ~ d a ~ M a r i n h a ~-~ I P q M ~}$
}

Received: November 29, 2007; Revised: February 27, 2008

\begin{abstract}
Sol-gel synthesis has been investigated in order to produce stoichiometric compositions of $\mathrm{Ba}_{3} \mathrm{Co}_{2} \mathrm{Fe}_{24} \mathrm{O}_{41}$ $\left(\mathrm{Co}_{2} \mathrm{Z}\right)$ at lower calcination temperatures, using citric acid as quelant complex. Using this method, $\mathrm{Co}_{2} \mathrm{Z}$ ferrite could be synthesized at $950{ }^{\circ} \mathrm{C}$, about $400{ }^{\circ} \mathrm{C}$ lower than that of conventional method. Nanocomposites $(80: 20 \%$ weight) of this ferrite with polychloroprene (CR) were obtained for the microwave absorption measurements by mixing, molding and curing mixtures of $\mathrm{Ba}_{3} \mathrm{Co}_{2} \mathrm{Fe}_{24} \mathrm{O}_{41}$ powders with polychloroprene and the additives of vulcanization. The microwave absorption measurements was carried out using the Transmission/Reflection method for the $\mathrm{S}$ and $\mathrm{X}-\mathrm{Ku}$ bands and showed the best performance as Radar Absorber Material (RAM) in 8.0-16.0 GHz range. Thus, the material can be used by reducing the radar signature of the Brazilian Frigates' superstructures.
\end{abstract}

Keywords: hexaferrite, microwave absorption, RAM, X-Ku frequencies

\section{Introduction}

Recently, UHF (ultra high frequency) devices have become necessary for application in miniaturized components ${ }^{1}$.

In this context, multi-layer chip inductor (MLCI) devices are outstanding as the most important passive surface mounting device (SMD) of the modern electronic industry ${ }^{1-3}$. The technology of MLCI greatly delayed from those of multi-layer chip capacitors and resistors; this feature in turn slowed down the development of the SMD technology in hyper frequency area ${ }^{2}$.

Hexagonal ferrites consist of a great family of ferromagnetic oxides with useful properties and there are many types of hexagonal ferrites (M, X, W, Y, Z and U). The Z-type barium hexaferrite $\left(\mathrm{Ba}_{3} \mathrm{Co}_{2} \mathrm{Fe}_{24} \mathrm{O}_{41}\right.$ or $\left.\mathrm{Co}_{2} \mathrm{Z}\right)$ can be used to manufacture of the abovereferred devices and has high performance in hyper-frequencies (100-1000 MHz).

Although $\mathrm{Co}_{2} \mathrm{Z}$ hexaferrite is promising, $\mathrm{NiZnCu}$ is still the ferrite commercially used for such application. The NiZnCu ferrite presents the disadvantage of have low resonance frequency. The spinel structure has a cut-off frequency below $300 \mathrm{MHz}^{2}$. The $\mathrm{Co}_{2} \mathrm{Z}$ hexaferrite can be considered as an ideal material to be used in MLCI for the band in the range of 300 to $1000 \mathrm{MHz}$, presenting high permeability, high dielectric constant and ferromagnetic resonance for 1 to $3 \mathrm{GHz}^{4}$.

Due to its complex crystalline structure, the necessary temperature for and sintering of the Z-type phase must $\mathrm{Co}_{2} \mathrm{Z}$ must be as high as $1300{ }^{\circ} \mathrm{C}$ when using conventional ceramic method (solid-state synthesis); chemical methods of synthesis have to be used in order to further decrease the sintering temperature ${ }^{3}$.

MLCI are obtained by tape-casting ferrite and screen printing internal electrode pastes alternately and then cofiring.

The citrate sol-gel method was developed to prepare homogeneous powders at lower temperature. In this method, the reactant cations are intimately mixed on the atomic scale, so the rate of the reaction will be increased, leading to lower synthesis temperatures and smaller particles. Then, by using this method it is possible to get a nanomaterial, with better homogeneity while using lower processing temperatures ${ }^{5,6}$.

Due the $\mathrm{Co}_{2} \mathrm{Z}$ complex chemical composition, any deviation from stoichiometry or the due oxidation states of the component-elements can cause an adverse effect in its magnetic properties ${ }^{5}$. The main advantage of the use of the citrate method is the homogeneity of the obtained material.

Some aspects of the synthesis need more attention, such as the $\mathrm{O}_{2}$ pressure. Oliveira and Ogasawara ${ }^{6}$, through Thermodynamic Analysis, concluded that both $\mathrm{H}_{2} \mathrm{O}(\mathrm{g})$ and $\mathrm{CO}_{2}(\mathrm{~g})$ becomes less harmful to hexaferrite formation and stability as the temperature of the system rises.

The use of inert atmosphere or pressures of $\mathrm{CO}_{2}(\mathrm{~g})$ and $\mathrm{H}_{2} \mathrm{O}(\mathrm{g})$ lower than $10^{-13}$ allows formation of the barium hexaferrite at relatively low temperatures, with minimum formation of $\mathrm{BaCO}_{3}$.

\section{Materials and Methods}

The ultrafine $\mathrm{Co}_{2} \mathrm{Z}$ powders were synthesized by using citrate precursor method, from $\mathrm{Fe}\left(\mathrm{NO}_{3}\right)_{3} \cdot 9 \mathrm{H}_{2} \mathrm{O}, \mathrm{Ba}\left(\mathrm{NO}_{3}\right)_{2}$, monohydrate citric acid and $\mathrm{Co}\left(\mathrm{NO}_{3}\right)_{2} \cdot 6 \mathrm{H}_{2} \mathrm{O}$ stoichiometric molar ratios to achieve $\mathrm{Ba}_{3} \mathrm{Co}_{2} \mathrm{Fe}_{24} \mathrm{O}_{41}$ ferrite. The preparation of the solutions was carried out weighting solids and placing then into adequate closed vessels submitted to super-dry nitrogen atmosphere. Distilled water was added to each one, under agitation, through syringes and needles until total dissolution of solids.

Then solutions have been transferred to a balloon and mixed therein; such balloon had been previously evacuated and then filled with super-dry nitrogen operated as a reflux condenser and intense stirring. The resultant mixture was heated up to $80{ }^{\circ} \mathrm{C}$ to have completed the reaction, under reflux in order to keep inert atmosphere inside the reaction vessel and to make possible future additions of $\mathrm{NH}_{4} \mathrm{OH}$. Ammonium hydroxide was added, dropwise into solution to make it neutral or slightly alkaline. In the later case, the $\mathrm{pH}$ is 
about 8.0, a condition suitable for subsequent precipitation of organometallic complex.

Each of several key-metal cations reacts with citric acid, under controlled $\mathrm{pH}$ conditions, to give the respective metal citrate, making up a homogeneous joint metallic citrate precursor complex.

Pre-dried ethanol was then added dropwise under vigorous stirring, into reacting mixture to promote the precipitation of a complex citrate gel of barium, iron and cobalt (see Figure 1).

After that the remaining aqueous solution was removed by drying at $70{ }^{\circ} \mathrm{C}$, thereby leaving the desired solid phase. All the synthesis process was carried out under super-dry nitrogen atmosphere in order to prevent the contact of the solutions with contaminants, mainly the carbon dioxide ${ }^{6-8}$.

Determination of an ideal temperature for the citrate gel decomposition, as well as all the behavior of the complex under heating was carried out by using thermogravimetric analysis (TGA) and differential thermal analysis (DTA). Based on results from this thermal analysis, the batch of dried solid was submitted to calcination inside muffle furnace whose temperature was varied from 600 to $1200{ }^{\circ} \mathrm{C}$.

The calcination was performed in the following heating schedule: $2{ }^{\circ} \mathrm{C} /$ minute up to $400{ }^{\circ} \mathrm{C}$, a $400{ }^{\circ} \mathrm{C}$ plateau during 1 hour, $10^{\circ} \mathrm{C} /$ minute up to the final sintering temperature with a residence time at the sintering temperature of 4 hours. Then, it was cooled at the rate of $10{ }^{\circ} \mathrm{C} /$ minute down to room temperature.

The calcined product was subjected to $\mathrm{X}$ ray diffraction (XRD) in order to assure the formation of the crystalline and magnetic phase of barium hexaferrite. Evaluation of the microstructure was performed by using a Topometrix II ${ }^{\circledR}$ Atomic Force Microscopy (AFM) and a Zeiss Scanning Electron Microscope (SEM) model DSM $940 \mathrm{~A}$, operating at acceleration voltages of $20 \mathrm{kV}, 24 \mathrm{kV}$ and $25 \mathrm{kV}$. Magnetic hysteresis measurements were performed by using the Vibrating Sample Magnetometry (VSM).

In order to obtain the composites for the measurement of the microwave absorber properties, the powder was mixed with polychloroprene rubber (CR), in a 80:20 concentration (ferrite: rubber, weight \%). The processing was carried out in a Berstorff two roll mill, at room temperature, with velocities of $22 \mathrm{rpm}$ (back) and $25 \mathrm{rpm}$ (forward). Vulcanized samples with $4.00 \times 4.00 \mathrm{~cm}$ and variable thickness were obtained by compression molding in a hydraulic press at $150{ }^{\circ} \mathrm{C}$ and $6.7 \mathrm{MPa}$. The vulcanization times were determined by the data obtained in the Monsanto Rheometer TM 100.

The microwave measurements conducted in this work were based on the Transmission/Reflection method (T/R) using a rectangular waveguide as the confining medium for the samples. Using the data obtained ( $\varepsilon^{\prime}, \varepsilon^{\prime \prime}, \mu$ 'and $\mu$ " values) from each of the samples measured, an expected prediction of the microwave reflectivity levels for the sheet absorbers was made by illustrating the variations of reflection loss (dB) vs. frequency $(\mathrm{GHz})$, using the HP 8510 network analyzer system. The materials were analyzed for the frequency range from 2.6 to $4.0 \mathrm{GHz}$ (S-band) and, from 8.0 to $16.0 \mathrm{GHz}$ (X/Ku-bands).

\section{Results and Discussion}

In turn, Figure 2 shows TG/ DTA curves of the gel. Above $400{ }^{\circ} \mathrm{C}$, there is no significant weight loss indicating that organic material was already completely eliminated ${ }^{9-10}$. From this information, decision

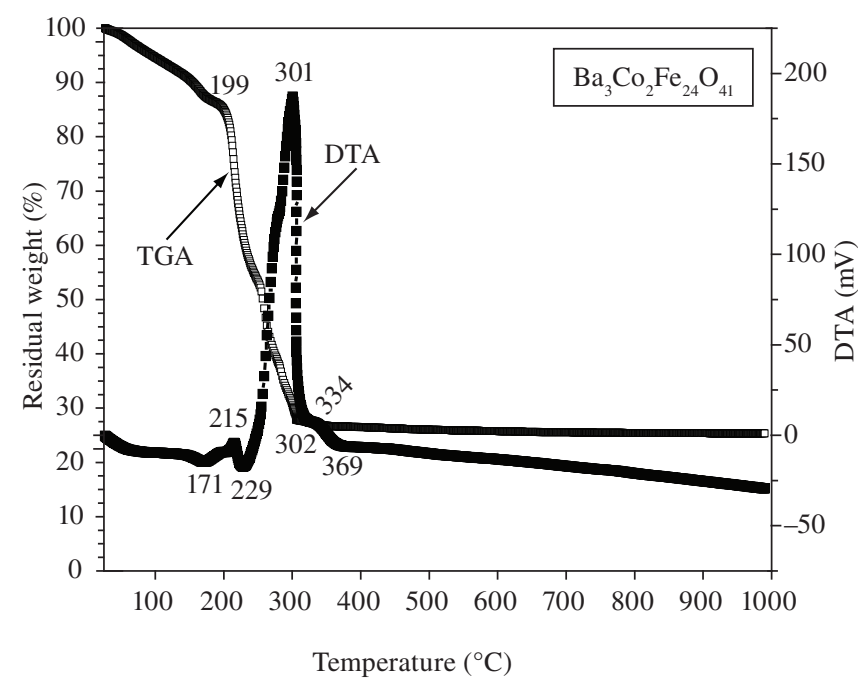

Figure 2. DTA and TGA curves for the metal citrate precursor behavior during heating, in air with heating rate of $10^{\circ} \mathrm{C} / \mathrm{min}$.<smiles>O=C(O)CC(O)(CC(=O)O)C(=O)O</smiles>

Citrate acid $+\quad \mathrm{M}^{+\mathrm{n}}$

Metalic ions<smiles>C[M]OC(CC(=O)O)(CC(=O)O)C(=O)O</smiles>

Metalic citrate<smiles>C[Y4]1OC(=O)C(CC(=O)O)(CC(=O)O)O1</smiles>

Metalic citrate<smiles>CCO</smiles>

Ethanol<smiles>CCOC(CC(=O)O)(CC(=O)O)C(=O)O</smiles>

Polymer

Complex citrate gel

Figure 1. Reactions in citrate precursor method. 
was taken to carry out gel calcination above $400{ }^{\circ} \mathrm{C}$; the crystalline nature of the powders was confirmed by XRD.

Unlike preparation of pure $\mathrm{BaFe}_{12} \mathrm{O}_{19}$ (M-type hexaferrite) by citrate precursor method, the Z-type phase powder can not be produced so easily due to the complexity of its structure, which imposes progressive transformation through intermediate ferrites before an achieving the final required structure.

The experimental results showed these transformations as being the following: a) at $600{ }^{\circ} \mathrm{C}$, were found out a mixture of hematite, $\mathrm{BaFe}_{2} \mathrm{O}_{4}, \mathrm{CoFe}_{2} \mathrm{O}_{4}, \mathrm{BaFe}_{12} \mathrm{O}_{19}$ (Ba M-type) and $\mathrm{Ba}_{2} \mathrm{Co}_{2} \mathrm{Fe}_{12} \mathrm{O}_{22}$ (Ba Y-type $)^{3}$; b) at $800{ }^{\circ} \mathrm{C}$, M-type and spinel phases were found; c) at $850{ }^{\circ} \mathrm{C}$, the product consisted of $\mathrm{Y}$ and $\mathrm{Z}$ phases; d) at $900{ }^{\circ} \mathrm{C}$, $\mathrm{Co}_{2} \mathrm{Z}$ had already become the predominant phase; and e) at $950{ }^{\circ} \mathrm{C}$, this Z-type phase was clearly the majority phase.

Then, the use of inert atmosphere effectively reduce the temperature required to form Z-type hexaferrite, a behavior remarkably different from that when the same starting mixture undergoes synthesis in air (instead of inert atmosphere), in which case calcined product consisted of: a) a mixture of $\mathrm{Y}$ and M-types at $1000{ }^{\circ} \mathrm{C}$; b) only at $1150{ }^{\circ} \mathrm{C}$ Z-type phase peaks were found out ${ }^{8}$.

However, this material synthesized in inert atmosphere contains according to Pullar et al. ${ }^{11}$ small undetectable amounts of Y-type phase $\left(\mathrm{Ba}_{2} \mathrm{Co}_{2} \mathrm{Fe}_{12} \mathrm{O}_{22}\right.$ ) coexisting with the Z-type phase.

AFM was used to characterize powders obtained at $950{ }^{\circ} \mathrm{C}$ (Figure 3). It is observed that the particles are uniform in size and this shape is sharply hexagonal plates with nanometric size.

To evaluate microstructure of the compacted material, disc-shaped compacts $(1.5 \mathrm{~cm}$ diameter and $0.5 \mathrm{~cm}$ height) obtained through dry pressing were analyzed by scanning electron microscopy (the samples were mounted on aluminum supports and coated with a film of gold).

Generally, large particles will sinter slower and require higher sintering temperatures or longer sintering times to attain an equivalent degree of densification. Surface diffusion and grain boundary diffusion are usually dominant with smaller particles sizes.

As shown in Figure 4, the fracture surface micrograph of sample sintered at $950{ }^{\circ} \mathrm{C} / 4$ hours reveals a well-densified material, which presents grains with hexagonal plate-like shape.

Magnetization of samples calcined at various temperatures (400, $500,600,700,800,850,900$ and $950{ }^{\circ} \mathrm{C}$ ) was measured by using vibrating-sample magnetometer at both room temperature and high temperature. Figure 5 shows the magnetic hysteresis curves of these samples.

An examination of these hysteresis curves led to the conclusion that the coercive force decreased as the sintering temperature increases, as a result of the also produced phase transformation. The coercive field $\left(\mathrm{H}_{c}\right)$ decreases with the temperature, which is in accordance with the disappearance of M-type hexaferrite phase (magnetically hard) and the formation of Z-type hexaferrite phase (magnetically soft). As determined by XRD (Figure 2), only at $950{ }^{\circ} \mathrm{C}$, the Z-type phase was clearly the majority phase

The powder without calcination presented magnetic properties, but it was a mixture of phases and the temperature improvement was necessary to obtain the $\mathrm{Co}_{2} \mathrm{Z}$ ferrite phase.

The sample composed of M-type and spinel ferrites, does not reach magnetic saturation because M-type ferrite has a very high anisotropic field. Obviously, the powder is a mixture of magnetically hard M-type phase and soft spinel phase.

The magnetization curves of the product synthesized in this work show typical features of magnetically soft materials and we can observe a decreasing coercive force $\left(\mathrm{H}_{c}\right)$ and the remanent magnetization $\left(\mathrm{B}_{\mathrm{r}}\right)$ when calcination temperature is increased, a behavior

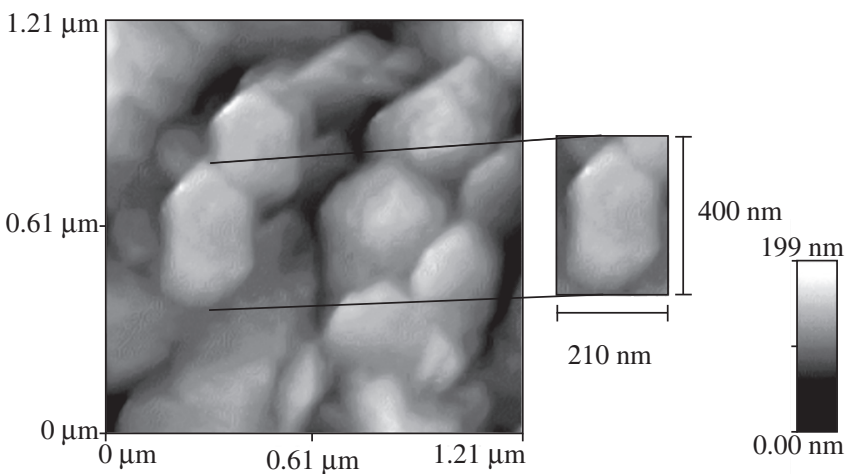

Figure 3. AFM micrograph of powder calcined at $950{ }^{\circ} \mathrm{C}$ in inert atmosphere (X 50000).

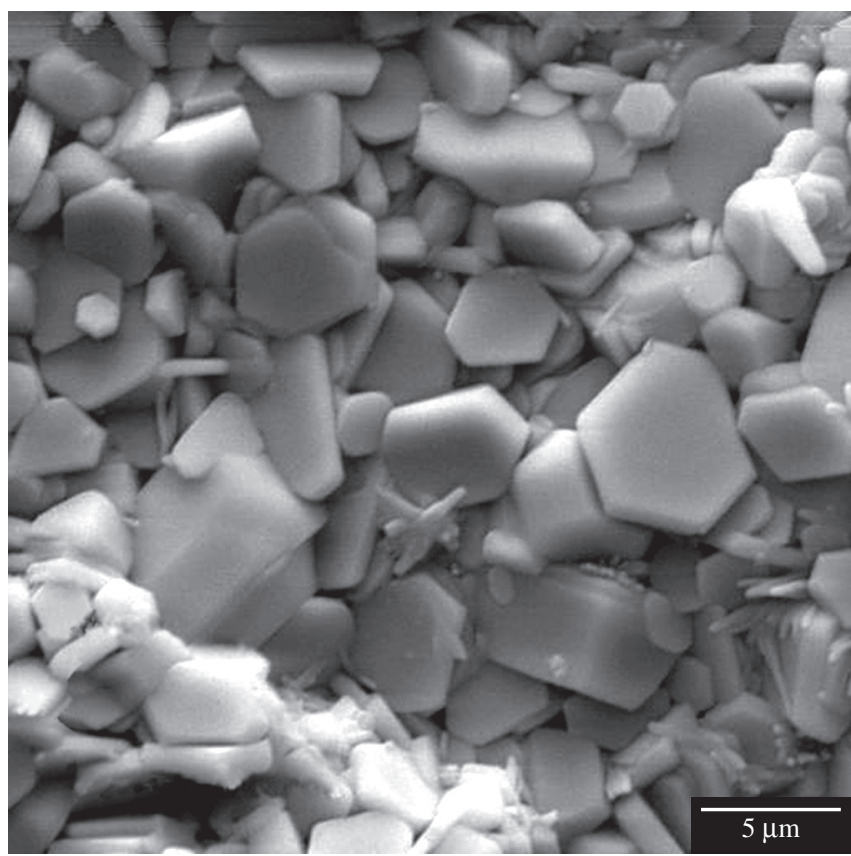

Figure 4. Fracture surface SEM microphotograph of $\mathrm{Co}_{2} \mathrm{Z}$ sintered at $950^{\circ} \mathrm{C}$.

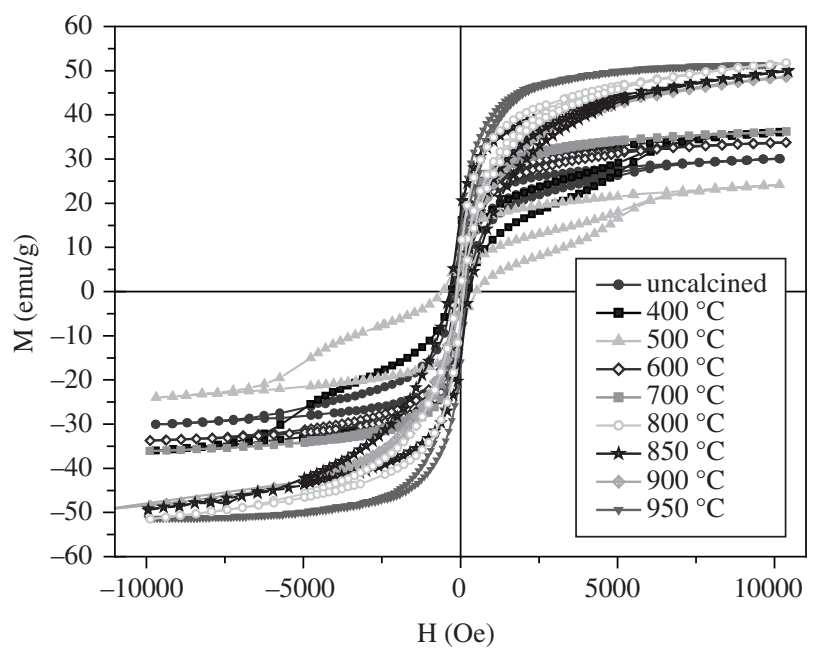

Figure 5. The magnetization curves at room temperature of the samples calcined at $400,500,600,700,800,850,900$ and $950^{\circ} \mathrm{C}$. 
consistent with the disappearance of the M-type phase and increasing Z-type phase ${ }^{6,7-12}$.

The powder calcined at $900{ }^{\circ} \mathrm{C}$ does not also presented magnetic saturation, which was only achieved in the product from calcination at $950{ }^{\circ} \mathrm{C}$ during 4 hours (magnetization of $45.1 \mathrm{emu} / \mathrm{g}$ and a coercive force of $110 \mathrm{Oe}$ ).

To study the microwave absorption properties of ferrite-polymer composites ( 80 wt. (\%) of $\mathrm{Ba}_{3} \mathrm{Co}_{2} \mathrm{Fe}_{24} \mathrm{O}_{41}$ composites with CR), the correlation between the magnetic properties and the frequency was investigated.

As know, the absorbing characteristics of the materials depend on the frequency, layer thickness, complex permittivity $\left(\varepsilon^{*}=\varepsilon '-\mathrm{j} \varepsilon^{\prime \prime}\right)$, and complex permeability ( $\left.\mu^{*}=\mu^{\prime}-\mathrm{j} \mu^{\prime \prime}\right)$. The absorbing characteristics could be varied by controlling the ferrite filler volume fraction in the composite materials.

The real and imaginary parts of the complex permeability $\left(\mu^{*}=\mu^{\prime}-\mathrm{j} \mu^{\prime \prime}\right)$, related to free-space, as a function of frequency are presented in Figure 6.

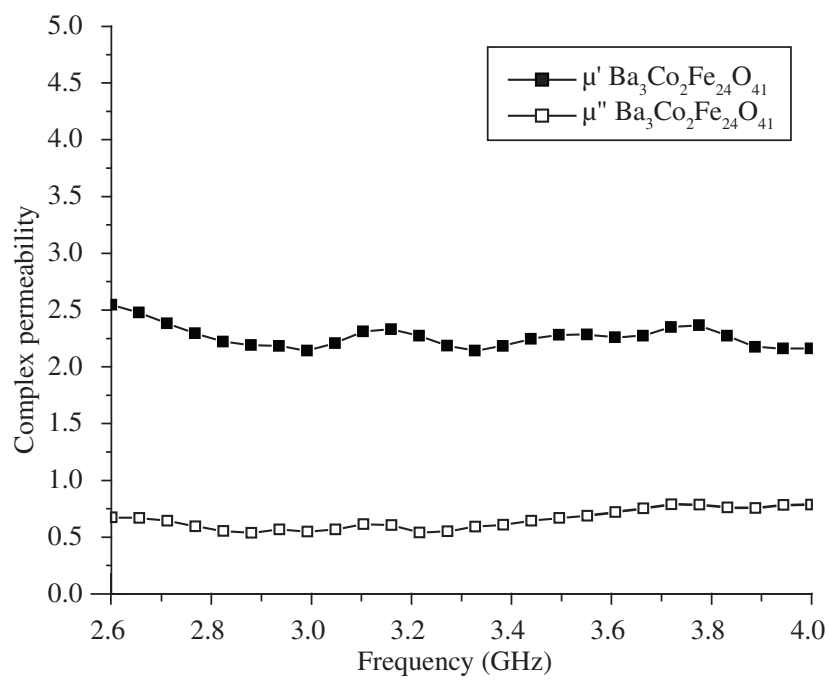

(a)

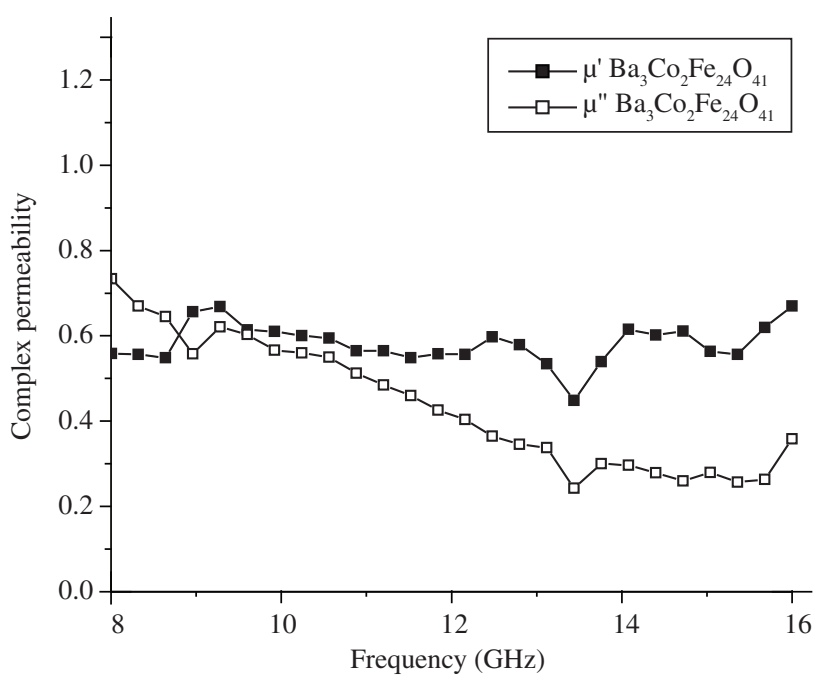

(b)

Figure 6. Complex pemeability $\left(\mu^{*}\right)$ as a function of frequency $(\mathrm{GHz})$ for $\mathrm{Ba}_{3} \mathrm{Co}_{2} \mathrm{Fe}_{24} \mathrm{O}_{41} / \mathrm{CR}$ composites (80/20, wt. (\%)), ( $\square$ real) and $\mathrm{x}$ ( $\square$ imaginary): a) S-band and b) X-kU bands.
As can be noticed from the Figure 6a, the permeability declines with frequency (S-band) from a value of approximately 2.5 to almost 2.2 for the real part ( $\left.\mu^{\prime}\right)$ and increases from 0.70 to 0.80 for the imaginary one ( $\mu$ ").

As shown in Figure $6 \mathrm{~b}$ to $\mathrm{X}-\mathrm{kU}$ band, the composite exhibited an increase in the real part of $\mu^{*}$ for the frequency range of $8.5-10.0 \mathrm{GHz}$, followed by a decline until $13.0 \mathrm{GHz}$. The imaginary part of $\mu^{*}$ exhibited a small peak between 9.0 and $10.0 \mathrm{GHz}$.

The relationship between the dielectric properties and the frequency has also been studied for a 80 wt. (\%) fraction of $\mathrm{Ba}_{3} \mathrm{Co}_{2} \mathrm{Fe}_{24} \mathrm{O}_{41}$ composites with CR composites, as can be observed from Figure 7.

The complex permittivity ( $\varepsilon^{*}=\varepsilon^{\prime}-\mathrm{j} \varepsilon$ ") of the composite remained practically unchanged for the frequency range 8.0-14.0 GHz and assumed a higher value of 8.0 for the real part of $\varepsilon^{*}$.

Using the data obtained ( $\varepsilon^{\prime}, \varepsilon$ ", $\mu$ ' and $\mu$ " values) for $\mathrm{S}$ and $\mathrm{X}-\mathrm{kU}$ bands, an expected prediction of the microwave reflectivity levels for the sheet absorbers was made. The results obtained from the reflectiv-

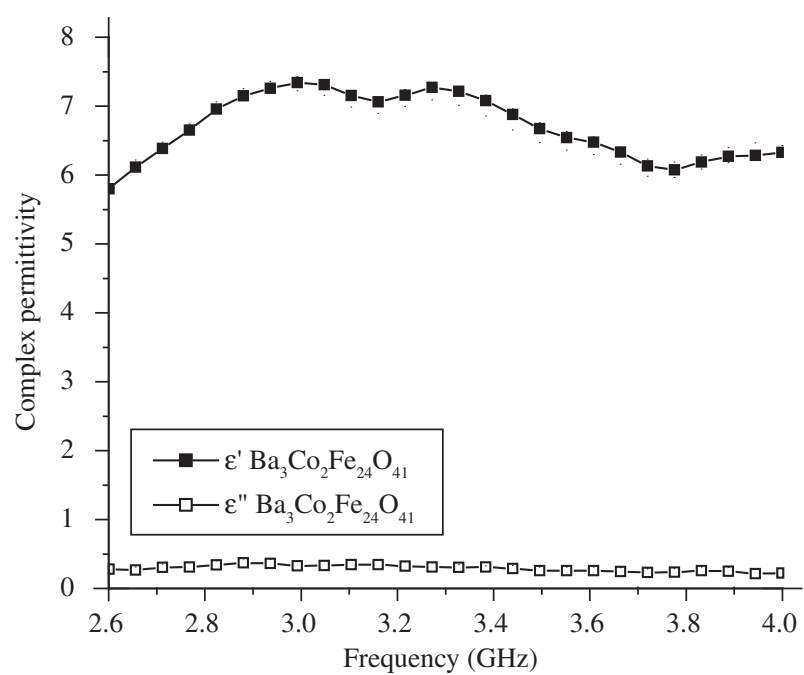

(a)

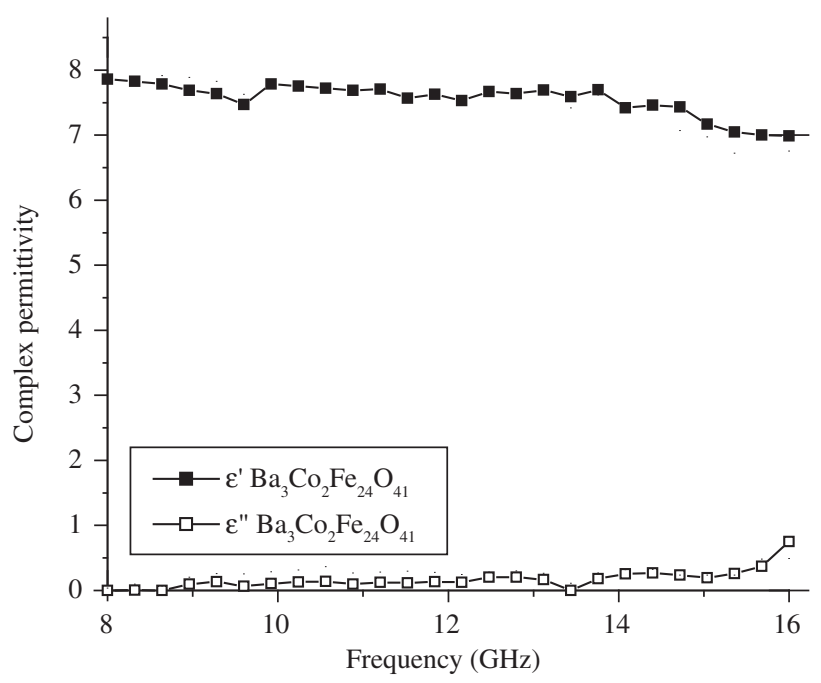

(b)

Figure 7. Complex permittivity $\left(\varepsilon^{*}\right)$ as a function of frequency $(\mathrm{GHz})$ for (for $\mathrm{Ba}_{3} \mathrm{Co}_{2} \mathrm{Fe}_{24} \mathrm{O}_{41} / \mathrm{CR}$ composites (80/20, wt. (\%)), ( real) and $\mathrm{x}$ ( $\square$ imaginary): a) S-band and b) X-kU bands. 
ity measurements (Reflection/Transmission Method) are illustrated in Figure 8, for different thickness of composites.

This material shows good microwave absorption at $\mathrm{X} / \mathrm{Ku}$ bands (8.0-16.0 GHz) for all thickness, as illustrated in Figure 9 by reduction of the reflection loss value $(\mathrm{dB})$.

From Figures 8 and 9, the composites showed good microwave absorption results for the frequency range analyzed. They showed microwave absorption greater than $90.0 \%$ (Reflection Loss $\leq-10 \mathrm{~dB}$ ), acting as a broadband RAM.

Figure 10 shows the morphology and good dispersion of Z-type hexaferrite in polychloroprene matrix (80:20, wt. (\%)) used to perform the microwave absorber measurements.
Figure 10 show the good dispersion of Z-type hexaferrite magnetic particles in polychloroprene matrix (80:20, wt. (\%)). From the SEM images, it can be seen that rubber mixing is a very good technique for the dispersion of the Z-type hexaferrites particles, in spite of the high weight concentration used ( $80 \%$ weight) and the tendency of these magnetic particles to form clusters and to induce demagnetizing fields.

Low temperature fired ferrite ceramic materials (Z-type hexaferrite) were obtained by citrate sol-gel process in inert atmosphere. The citrate sol-gel method has the advantages of both wet-chemical and solid-state synthesis methods, such as low temperature synthesis $\left(\sim 950{ }^{\circ} \mathrm{C}\right)$, well-dispersed nanoparticles, inexpensive precursors, ease of preparation.

Frequency $(\mathrm{GHz})$

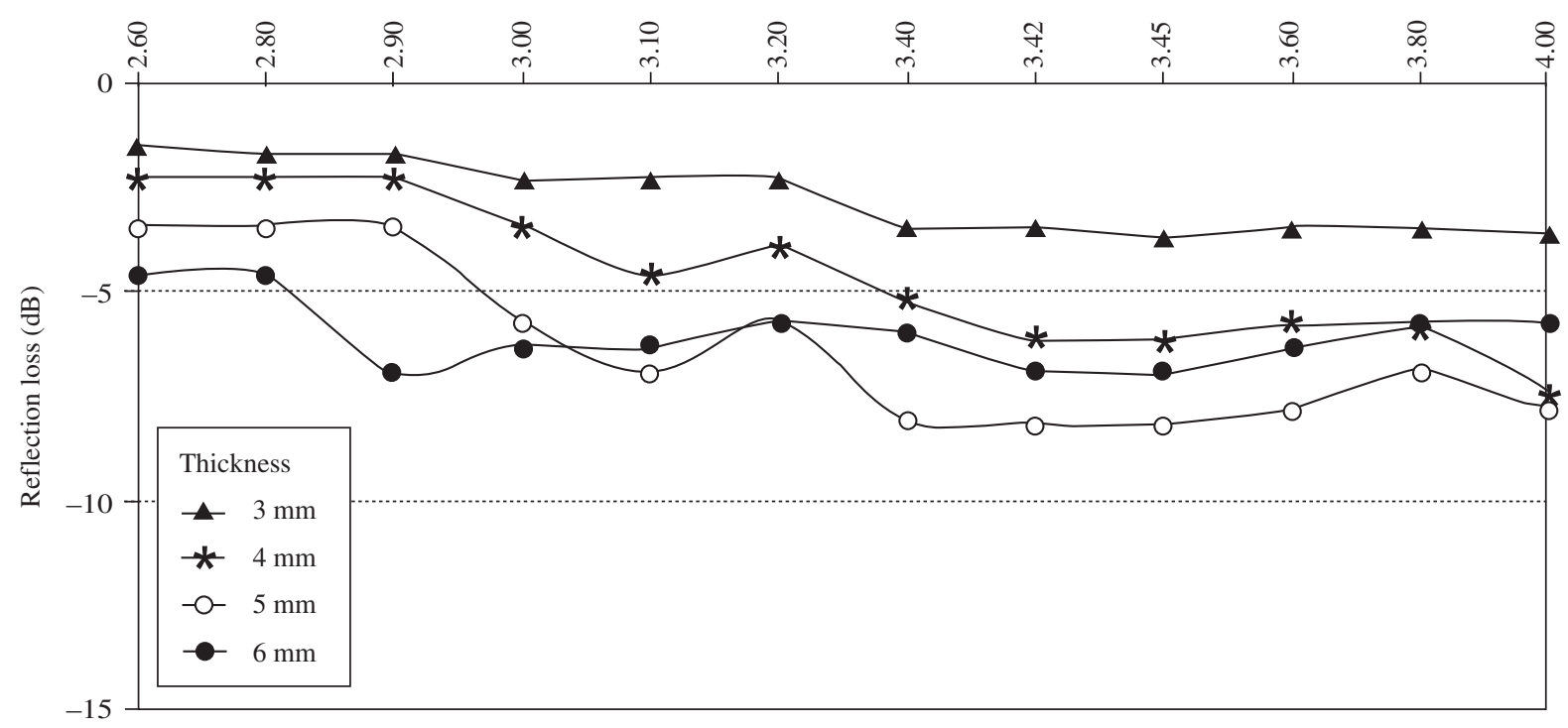

Figure 8. Reflection loss $(\mathrm{dB})$ as a function of frequency $(\mathrm{GHz})$ in S-band $(2.6-4.0 \mathrm{GHz})$.

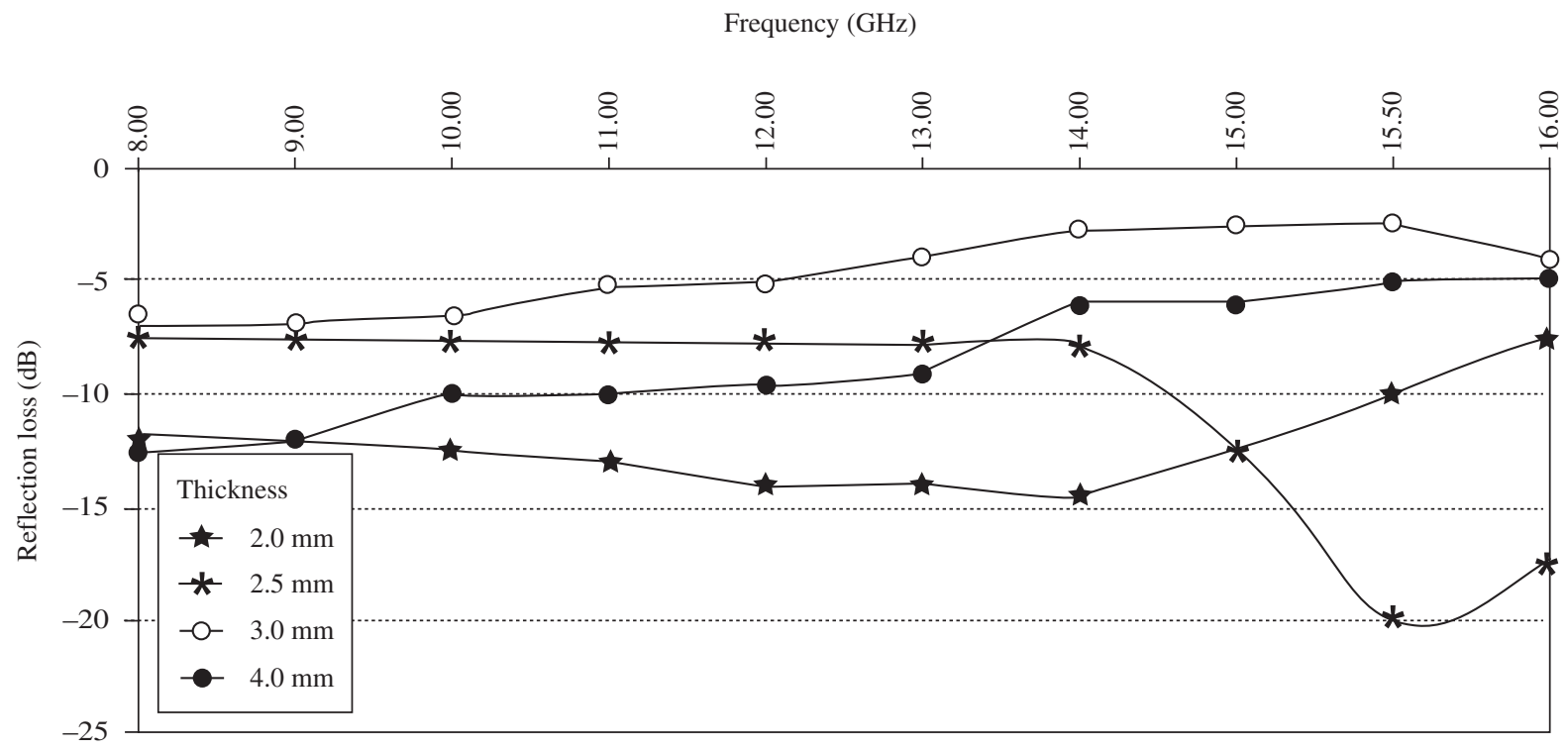

Figure 9. Reflection loss $(\mathrm{dB})$ as a function of frequency $(\mathrm{GHz})$ in $\mathrm{X} / \mathrm{Ku}$-bands $(8.0-16.0 \mathrm{GHz})$. 


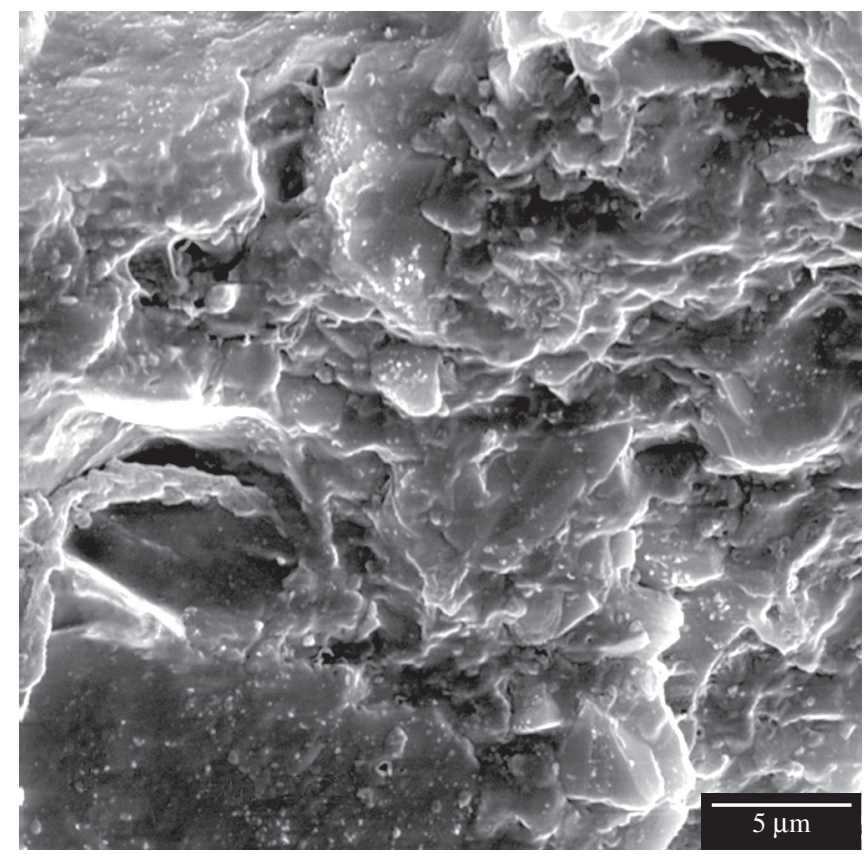

Figure 10. Scanning electron micrograph of $\mathrm{Ba}_{3} \mathrm{Co}_{2} \mathrm{Fe}_{24} \mathrm{O}_{41}$ hexaferrite: polychloroprene (80:20, wt. (\%)) used to perform the microwave absorber measurements. Magnification $=3000$.

This method allowed the production of Z-type barium hexaferrite possessing very good magnetic properties and resulting in a stealth technological product with a microwave absorption greater than $90.0 \%$ for the frequencies analyzed, acting as a broadband RAM, with the greatest microwave absorption of $99 \%$ (reflectivity of $-20 \mathrm{~dB}$ ) at $15.5 \mathrm{GHz}$.

\section{Acknowledgements}

The authors gratefully acknowledge the financial support and other forms of aid provided by CNPq, FAPERJ, PEMM/COPPE, CBPF, IF/UFRJ, IPqM and PETROBRAS, which were crucial for the success of this research.

\section{References}

1. Cramer DC. Overview of Technical, Engineering, and Advanced Ceramics. In: Engineered Materials Handbook: Ceramics and Glasses. New York, USA: ASM International; 1998. p. 16-20.

2. Deconihout B, Pareige C, Pareige P, Blavette D, Menand A. Tomographic Atom Probe: New Dimension in Materials Analysis. Microscopy and Microanalysis 1999; 5(1):39-47.

3. Zhang H, Zhou J, Yue Z, Wu P, Gui Z, Li L. Synthesis of $\mathrm{Co}_{2} \mathrm{Z}$ hexagonal ferrite with planar structure by gel self-propagating method. Materials Letters 2000; 43(1-2):62-65.

4. Wang Z, Li L, Su S, Gui Z, Yue Z, Zhou J. Low-temperature sintering and high frequency properties of Cu-modified Co2Z hexaferrite. J. Eur. Cer. Soc. 2003; 23(5):715-720.

5. Zhang H, Zhou J, Li L, Yue Z, Gui Z. Dielectric characteristics of novel Z-type planar hexaferrite with $\mathrm{Cu}$ modification. Materials Letters 2002; 55(6):351-355.

6. Caffarena VR. Study of the Magnetic and Microwave Absorber Properties of Z-Type Barium Hexaferrite Obtained by Citrate Precursor Method. [Tese Doutorado]. Rio de Janeiro: Universidade Federal do Rio de Janeiro; 2004.

7. Pinho MS, Gregori ML, Nunes RCR, Soares BG. Performance of Radar Absorbing Materials by Waveguide Measurements for $\mathrm{X}$ and $\mathrm{Ku}-\mathrm{Band}$ Frequencies. Eur. Pol. J. 2002; 38(11):2321-2327.

8. Ogasawara T, Oliveira MAS. Microstructure and hysteresis curves of the barium hexaferrite from co-precipitation by organic agent. J. Magn. Mag. Mat. 2000; 217(1-3):147-154.

9. Caffarena VR, Ogasawara T, Capitaneo JL, Pinho MS. Characterization of the Z-type hexaferrite doped with cobalt and zinc obtained by coprecipitation method. Science and Technology 2004.

10. Austissier D, Podembski A, Jacquiod DC. Microwaves properties of M and Z type hexaferrites. J.Phys. IV France 1997; 7(C1):409-412.

11. Pullar RC. The manufacture and characterization of aligned fibres of the ferroxplana ferrites $\mathrm{Co}_{2} \mathrm{Z}, 0.67 \% \mathrm{CaO}$-doped $\mathrm{Co}_{2} \mathrm{Z}, \mathrm{Co}_{2} \mathrm{Y}$ and $\mathrm{Co}_{2} \mathrm{~W}$. J. Magn. Magn. Mat. 1998; 186(3):313-325.

12. Caffarena VR, Ogasawara T, Capitaneo JL, Pinho MS. Magnetic Properties of Z-Type $\mathrm{Ba}_{3} \mathrm{Co}_{13} \mathrm{Zn}_{03} \mathrm{Cu}_{04} \mathrm{Fe}_{24} \mathrm{O}_{41}$ Nanoparticles. Mat. Chem. and Phys. 2007; 101(1):81-86. 